\title{
Long-term survival of femoral neck fracture patients aged over ninety years: Arthroplasty compared with nonoperative treatment
}

\author{
Yang Liu" ${ }^{1 *}$, Chong-wei Zhang ${ }^{2}$ and Xiao-dan Zhao ${ }^{1}$
}

\begin{abstract}
Background: The aging of the Chinese population is expected to lead to an increase in nonagenarians and centenarians. The mortality rate in nonagenarian hip fracture patients is equivalent to the mortality rate in the average population at 5 years after injury. It is imperative to evaluate 5 -year mortality in this small but very challenging subgroup of patients to optimize patient management. The primary purpose of the current retrospective study was to compare five-year survival in patients aged over 90 years who received arthroplasty or nonoperative treatment for femoral neck fracture during a 16-year period.
\end{abstract}

Methods: From January 1998 to December 2014, all consecutive nonagenarian and centenarian patients with femoral neck fracture admitted to our hospital were included in the evaluation. The primary outcome was defined as thirty-day, 1-year, 3-year, and 5-year mortality after injury. Survival analysis was performed with the Kaplan-Meier method. Using the log-rank test, stratified analyses were performed to compare differences in the overall cumulative mortality and mortality at three time points ( 1 year, 3 years, and 5 years) after injury and differences in survival distributions.

Results: Over the 16-year study period, the arthroplasty group and the nonoperative treatment group included 33 and 53 patients, respectively. The long-term survival probability of the arthroplasty group was significantly higher than that of the nonoperative treatment group $(p=0.002)$. The survival time of the arthroplasty group was significantly higher than that of the nonoperative treatment group (median $\left(P_{75}-P_{25}\right)=53$ (59) versus median $\left(P_{75^{-}}\right.$ $\left.\left.P_{25}\right)=22(52), p=0.001\right)$. The mortality differences, except for 30-day mortality, at five time points $(1,2,3$, 4, and 5 years) between the nonoperative group and arthroplasty group were significant. The stratified analyses of overall cumulative mortality and mortality at three time points (1,3, and 5 years) after injury demonstrated that the nonoperative treatment group had significantly higher cumulative mortality than the arthroplasty group.

Conclusions: Our study demonstrates that arthroplasty is more likely to improve long-term survival in femoral neck fracture patients aged over 90 years than nonoperative treatment. It can be expected that nearly half of patients will survive more than 5 years after surgery.

\footnotetext{
*Correspondence: ly196818@163.com

'Department of Orthopedic Surgery, National Clinical Research Center for Geriatrics, West China Hospital of Sichuan University, Wai Nan Guo Xue Lane No. 37, Wuhou District, Chengdu, Sichuan Province, P.R. China 610041

Full list of author information is available at the end of the article
}

(c) The Author(s). 2020 Open Access This article is licensed under a Creative Commons Attribution 4.0 International License, which permits use, sharing, adaptation, distribution and reproduction in any medium or format, as long as you give appropriate credit to the original author(s) and the source, provide a link to the Creative Commons licence, and indicate if changes were made. The images or other third party material in this article are included in the article's Creative Commons licence, unless indicated otherwise in a credit line to the material. If material is not included in the article's Creative Commons licence and your intended use is not permitted by statutory regulation or exceeds the permitted use, you will need to obtain permission directly from the copyright holder. To view a copy of this licence, visit http://creativecommons.org/licenses/by/4.0/ The Creative Commons Public Domain Dedication waiver (http://creativecommons.org/publicdomain/zero/1.0/) applies to the data made available in this article, unless otherwise stated in a credit line to the data. 


\section{Background}

The aging of the Chinese population is expected to lead to an increase in nonagenarians and centenarians. Chinese people comprised approximately $15 \%$ of the global population over 90 years of age at the end of 2017 [1]. Mortality in people aged over 80 years reaches a "plateau" after age 105 [2]. Thus, the extended life expectancy of elderly individuals profoundly influences many aspects of medical care.

Hip fracture ranks among the top 10 causes of disability and mortality in the elderly population [3]. Intracapsular femoral neck fractures account for $50 \%$ of all hip fractures [3]. The age-specific incidence of hip fracture in elderly Chinese individuals has increased during the last decade $[4,5]$. Accordingly, femoral neck fracture in extremely elderly individuals in China represents a tremendous burden on the public health system.

Although extensive studies on 30-day or 1-year mortality in femoral neck fracture patients aged above 90 years exist, very little data on 2 -year or 5year survival in these patients exist [6-9]. The additional life expectancy for nonagenarian hip fracture patients is $4-5$ years $[10,11]$. Moreover, recent studies demonstrated that the mortality rates in nonagenarian hip fracture patients returned to a rate equivalent to that in the average population at 5 years after injury $[9,12-15]$. Therefore, it is imperative to evaluate 5-year mortality in this small but very challenging subgroup of patients to optimize patient management.

Currently, there is no consensus regarding the longterm survival of hip fracture patients over 90 years of age. Few articles have discussed five-year survival in nonagenarians $[9,16,17]$. Furthermore, less than $5 \%$ of patients survive for more than 10 years [16]. Thus, several authors considered 5-year survival as a long-term survival result in this extremely elderly population [17].

The primary purpose of the current retrospective study was to compare five-year survival in patients aged over 90 years who receive arthroplasty or nonoperative treatment for femoral neck fracture during the same 16year period.

\section{Methods}

From January 1998 to December 2014, all consecutive nonagenarian and centenarian patients with femoral neck fracture admitted to our hospital were included for evaluation. Patients with polytrauma, open fractures, pathological fractures, femoral head fractures, subtrochanteric fractures, or intertrochanteric fractures were excluded from this study. The follow-up endpoint was defined as the date of death or emigration or 1 April 2019, whichever came first, and survival was determined at this time. The institutional review board of our academic hospital approved this study.

The goal of care discussion was typically attended by the patient, their family, and representatives from the medical hip fracture co-management service and orthopedic surgery unit. The purpose of this discussion was to listen to the patient to understand their previous and current quality of life and ensure that an informed decision was being made. Nonoperative management was undertaken only when requested by the patient or their family.

According to the different treatment regimens (nonoperative treatment versus arthroplasty), we divided the patients into the nonoperative group and arthroplasty group. Seven senior surgeons performed the arthroplasty procedures (including total hip arthroplasty and hemiarthroplasty).

\section{Covariates}

The collected data included age, sex, injury side, comorbidities, length of stay, body mass index (BMI), in-hospital complications, transfusion amount, hyperthermia, intensive care unit (ICU) stay, mortality date, and 30-day readmission obtained from the hospital's patient management system. Detailed definitions of admission laboratory parameters are available in the User Guide for the ACS NSQIP Participant Use File [18].

\section{Comorbidities}

Comorbidities on admission were assessed by the Charlson comorbidity index (CCI) [19] and the American Society of Anesthesiologists (ASA) physical status classification [20]. The CCI determines the comorbidity level according to the number and severity of 19 predefined conditions. The CCI is the most popular tool for evaluating comorbidities in clinical studies. Because the study participants included only patients aged over 90 years, the age-adjusted variant of the CCI was not used. The ASA grading scale includes five classes, from Class I to Class V. No patient in this study was graded as Class V. The ratings were divided into two categories: Class I or II and Class III or IV.

\section{Complications}

Complications were categorized as cardiac, pulmonary, gastrointestinal, urologic, or cerebrovascular. Cardiac complications included acute myocardial infarction, arrhythmia, congestive heart failure exacerbation, and unexplained hypotension. Pulmonary complications included acute respiratory failure, prolonged intubation, and pneumonia. Gastrointestinal complications included obstruction, perforation, and bleeding. Urological complications included urinary tract infection and urinary 
retention. Cerebrovascular manifestations included cerebral vascular accident and pulmonary embolism. Each type of complication was then transformed into a bivariate variable to define whether a patient did or did not have the complication.

\section{Mortality data}

The mortality date of the participants in both groups was obtained from the National Public Security System (NPSS) and the three primary health insurance schemes in China: Urban Resident Basic Medical Insurance (URBMI), Urban Employee Basic Medical Insurance (UEBMI), and the New Rural Cooperative Medical Scheme (NRCMS). These register systems include the survival status of all citizens and are updated annually. If the mortality date was not retrievable from the system, it was retrieved through local community registration charts, nursing homes, or telephone follow-ups. We defined short-term mortality as death occurring more than 30 days but less than 12 months after femoral neck fracture and long-term mortality as death occurring 5 years after fracture. The primary outcome was defined as 30day mortality and 1-year, 2-year, 3-year, 4-year, and 5year mortality after injury.

\section{Statistical analysis}

Data were analyzed with the 22.0 IBM SPSS statistical package (SPSS Inc., USA) for Windows. The results are expressed as means \pm standard deviations (SDs), medians [25-75 quartiles] for nonnormally distributed quantitative data or numbers (percentages), and 95\% confidence intervals. The normally distributed variables were assessed using an independent $\mathrm{t}$-test and a chi-square test. When comparing two independent samples with a non-normal distribution, the Wilcoxon rank-sum test was used. Survival status between the two groups was analyzed by the Kaplan-Meier method for all-cause mortality. Using the log-rank (Mantel-Cox) test, stratified analyses of overall cumulative mortality and mortality at three-time points ( 1 year, 3 years, and 5 years) after injury were performed to compare the differences in survival distributions. A two-sided significance test was performed for all tests, and a $p$-value $<0.05$ was considered statistically significant.

\section{Results}

Over the 16-year study period, 89 femoral neck fracture patients aged over 90 years were admitted to our hospital. Among them, one patient was excluded because he underwent internal fixation $(2.8 \%, 1 / 35,1$ hip). In the arthroplasty group, one patient $(2.8 \%, 1 / 35,1$ hip) was excluded from this review because they underwent arthroplasty in another hospital. The survival data of 1 patient in the nonoperative treatmentgroup $(1.8 \%, 1 / 54$, one hip) were not retrievable; therefore, these three patients were excluded from the final statistical analysis.

Finally, 86 patients, including 43 women (50\%), and 43 men (50\%), were included in the study. The arthroplasty group and the nonoperative treatment group included 33 and 53 patients, respectively. The median age of the arthroplasty group and the nonoperative group was 92 (90-104) years and 91.5 years (90-103), respectively. The baseline characteristics of the two groups are shown in Table 1.

The differences in the rates of delirium, pressure ulcers, hematocrit $(\mathrm{HCT})<0.30$, and low albumin (ALB), as well as the number of transfusions of red cells and plasma between the nonoperative group and arthroplasty group, was statistically significant (Table 1). Other baseline variables between the two groups were not significantly different.

Subsequent stratified analyses indicated that in terms of the ASA grade, CCI score, and age, the differences between the two groups were not significant (Table 2). However, the long-term survival in the arthroplasty group was significantly higher than that in the nonoperative treatment group (39.3\%,13/33 versus $11.3 \%, 6 / 53$, $p=0.002$ ). Expectedly, the length of stay in the arthroplasty group was higher than that in the nonoperative treatment group (Table 3).

The survival time in the arthroplasty group was significantly longer than that in the nonoperative treatment group (median $\left(\mathrm{P}_{75^{-}}-\mathrm{P}_{25}\right)=53$ (59) versus median $\left(\mathrm{P}_{75^{-}}\right.$ $\left.\left.\mathrm{P}_{25}\right)=22(52), p=0.001\right)$. Through the last follow-up, the longest survival times in the two groups was 175 months in the arthroplasty group and 93 months in the nonoperative treatment group. The Wilcoxon rank-sum test also demonstrated that the differences in BMI and serum sodium levels at admission between the two groups were significant (Table 3).

The cumulative mortality after injury in the 30-day, 1year, 2-year, 3-year, 4-year and 5-year nonoperative group versus arthroplasty groups were $17.0 \%$ versus 9.1 , $43.4 \%$ versus $12.1,50.9 \%$ versus $24.2,64.2 \%$ versus 39.4 , $71.7 \%$ versus 45.5 , and $79.2 \%$ versus $51.5 \%$, respectively (Table 4). The overall cumulative mortality in the nonoperative group was 1.5 -fold higher than that in the arthroplasty group. The difference between the two groups was significant $(p=0.007)$. The differences in mortality, except for 30-day mortality, at five-time points ( 1 year, 2 years, 3 years, 4 years, and 5 years) between the nonoperative treatment group and arthroplasty group were significant.

Table 5 demonstrates that the survival rates in the arthroplasty group at six different time intervals (30 
Table 1 Chi-square test compares the baseline variable of the two groups with a normal distribution

\begin{tabular}{|c|c|c|c|c|}
\hline \multirow[t]{2}{*}{ Variable } & \multicolumn{2}{|l|}{ Treatment regime groups } & \multirow[t]{2}{*}{$x^{2}$} & \multirow[t]{2}{*}{$P$} \\
\hline & Nonoperative group n(\%) & Arthroplasty group n(\%) & & \\
\hline \multicolumn{5}{|l|}{ Gender } \\
\hline Female & $27(62.8)$ & $16(37.2)$ & \multirow[t]{2}{*}{0.049} & \multirow[t]{2}{*}{0.825} \\
\hline Male & $26(60.5)$ & $17(39.5)$ & & \\
\hline \multicolumn{5}{|l|}{ Fracture side } \\
\hline Left & $28(65.1)$ & $15(34.9)$ & \multirow[t]{2}{*}{0.443} & \multirow[t]{2}{*}{0.506} \\
\hline Right & $25(58.1)$ & $18(41.9)$ & & \\
\hline \multicolumn{5}{|l|}{ Complications } \\
\hline Pulmonary complications & $32(72.7)$ & $12(27.3)$ & 3.101 & 0.078 \\
\hline Peptic ulcer disease & $5(62.5)$ & $3(37.5)$ & $0.003^{\mathrm{a}}$ & $0.958^{b}$ \\
\hline UTI & $4(57.1)$ & $3(42.9)$ & $0.065^{\mathrm{a}}$ & $0.799^{b}$ \\
\hline Cardiac Complications & $6(60.0)$ & $4(40.0)$ & $0.013^{\mathrm{a}}$ & $0.910^{\mathrm{b}}$ \\
\hline Cerebrovascular complications & $8(100.0)$ & $0(0.0)$ & $3.849^{\mathrm{a}}$ & $0.050^{\mathrm{b}}$ \\
\hline DVT & $9(90.0)$ & $1(10.0)$ & $2.614^{\mathrm{a}}$ & $0.106^{b}$ \\
\hline Delirium & $26(74.3)$ & $9(25.7)$ & 3.999 & $0.046^{*}$ \\
\hline Pressure ulcers & $20(83.3)$ & $4(16.7)$ & 6.632 & $0.010^{*}$ \\
\hline Hyperthermia & $13(48.1)$ & $14(51.9)$ & 3.024 & 0.082 \\
\hline \multicolumn{5}{|l|}{ Commodity } \\
\hline Diabetes mellitus & $5(41.7)$ & $7(58.3)$ & $1.471^{\mathrm{a}}$ & $0.225^{b}$ \\
\hline COPD & $34(69.4)$ & 15 (30.6) & 2.900 & 0.089 \\
\hline Renal disease & $9(81.8)$ & $2(18.2)$ & $1.306^{\mathrm{a}}$ & $0.257^{b}$ \\
\hline Coronary artery disease & $5(50.0)$ & $5(50.0)$ & $0.210^{\mathrm{a}}$ & $0.647^{b}$ \\
\hline Commobidity Hypertension & $21(56.8)$ & $16(43.2)$ & 0.652 & 0.420 \\
\hline Commobidity UTI & $2(50.0)$ & $2(50.0)$ & $0.240^{\mathrm{a}}$ & $0.624^{b}$ \\
\hline Commobidity Stoke & $9(81.8)$ & $2(18.2)$ & $1.306^{\mathrm{a}}$ & $0.253^{b}$ \\
\hline \multicolumn{5}{|l|}{ Admission laboratory parameters } \\
\hline Low HGB(<12 g/dL) & $30(61.2)$ & 19 (38.8) & 0.008 & 0.929 \\
\hline Low HCT (<30\%) & $14(87.5)$ & $2(12.5)$ & 5.564 & $0.018^{*}$ \\
\hline Low WBC count $(<4500 / m c L)$ & $2(50.0)$ & $2(50.0)$ & $0.240^{\mathrm{a}}$ & $0.624^{b}$ \\
\hline High WBC count(> 10,000/mcL) & $14(66.7)$ & $7(33.3)$ & 0.298 & 0.585 \\
\hline Low platelets (<150,000/mcL) & $23(62.2)$ & $14(37.8)$ & 0.008 & 0.929 \\
\hline High INR (> 1.1) & $23(71.9)$ & $9(28.1)$ & 2.263 & 0.133 \\
\hline High BUN (> 30 mg/dL) & $15(71.4)$ & $6(28.6)$ & 1.129 & 0.288 \\
\hline Creatinine (> $1.3 \mathrm{mg} / \mathrm{dL})$ & $9(60.0)$ & $6(40.0)$ & 0.020 & 0.887 \\
\hline Low ALB<34G/L & $29(80.6)$ & $7(19.4)$ & 9.381 & $0.002 *$ \\
\hline High Bilirubin (> 1.9 mg/dL) & $3(60.0)$ & $2(40.0)$ & $0.006^{\mathrm{a}}$ & $0.939^{b}$ \\
\hline High sodium (> 145 mEq/L) & $1(25.0)$ & $3(8.1)$ & $1.033^{\mathrm{a}}$ & $0.310^{\mathrm{b}}$ \\
\hline Low sodium (< 135 mEq/L) & $15(65.2)$ & $8(34.8)$ & 0.171 & 0.679 \\
\hline \multicolumn{5}{|l|}{ Transfusion } \\
\hline Number of Transfusion Red cell & $8(30.8)$ & $18(69.2)$ & 15.001 & $<0.001^{*}$ \\
\hline Number of Transfusion Plasma & $4(30.8)$ & $9(69.2)$ & $4.726 a$ & $0.030^{\mathrm{b} *}$ \\
\hline ICU stay & $5(55.6)$ & $4(44.4)$ & $0.001 a$ & $0.973^{b}$ \\
\hline 30-day re-admission & $8(80.0)$ & $2(20.0)$ & $0.856 a$ & $0.355^{b}$ \\
\hline
\end{tabular}

* $P<0.05$ was considered statistically significant. $\boldsymbol{a}$. The chi-square test of continuous correction was used, and the expected count of the cell was less than 5 and greater than $1 . \boldsymbol{b}$. Continuous correction chi of square test significance (2-sided) 
Table 2 The stratified analyses of ASA, CCl, age, and survival patient number of two groups

\begin{tabular}{|c|c|c|c|c|}
\hline \multirow[t]{2}{*}{ Variable } & \multicolumn{2}{|l|}{ Treatment regime groups } & \multirow[t]{2}{*}{$x^{2}$} & \multirow[t]{2}{*}{$P$} \\
\hline & Nonoperative group n(\%) & Arthroplasty group n(\%) & & \\
\hline \multicolumn{5}{|l|}{ ASA } \\
\hline $10 r 2$ & $27(60.0)$ & $18(40.0)$ & 0.056 & 0.813 \\
\hline $30 r 4$ & $26(63.4)$ & $15(36.6)$ & & \\
\hline \multicolumn{5}{|l|}{$\mathrm{CCl}$} \\
\hline 0or1 & $18(50.0)$ & $18(50.0)$ & 4.508 & 0.105 \\
\hline 2 & $11(61.1)$ & $7(38.9)$ & & \\
\hline$\geq 3$ & $24(75.0)$ & $8(25.0)$ & & \\
\hline \multicolumn{5}{|l|}{ Age-stratified } \\
\hline $90-94$ years & $41(62.1)$ & $25(37.9)$ & 0.029 & 0.864 \\
\hline$\geq 95$ years & $12(60.0)$ & $8(40.0)$ & & \\
\hline \multicolumn{5}{|c|}{ Long-term survival probability } \\
\hline Survival $>5$ years & $6(31.6)$ & $13(68.4)$ & 9.31201 & $0.002^{*}$ \\
\hline Survival $<5$ years & $47(70.1)$ & $20(29.9)$ & & \\
\hline
\end{tabular}

* $P<0.05$ was considered statistically significant

days, 1 year, 2 years, 3 years, 4 years, and 5 years) were significantly higher than those in the nonoperative group. The overall survival time in the arthroplasty group was also higher than that in the nonoperative group ( $p=$ 0.002). As a secondary analysis, survival status analysis of the two groups was performed with a Kaplan-Meier survival curve for all-cause mortality. As presented in Fig. 1, using the log-rank (Mantel-Cox) test, the stratified analyses of overall cumulative mortality and mortality at three time points ( 1 year, 3 years, and 5 years) after injury demonstrated that the nonoperative treatment group had significantly higher cumulative mortality than the arthroplasty group.

\section{Discussion}

According to our study, the cumulative five-year mortality rates in the arthroplasty group and nonoperative treatment group were 51.5 and $79.2 \%$, respectively. Femoral neck fracture patients over 9 years of age can benefit from arthroplasty surgery. Our study suggested that patients who received nonoperative treatment had higher rates of short- and long-term mortality than those who underwent surgery. They also had a shorter mean survival times than arthroplasty patients. Additionally, the annual mortality in the arthroplasty group was significantly lower than that in the nonoperative treatment group. To our knowledge, the current study is

Table 3 The Wilcoxon Rank - Sum test for two variables without a normal distribution between two groups

\begin{tabular}{|c|c|c|c|c|}
\hline \multirow[t]{2}{*}{ Variables } & \multicolumn{2}{|l|}{ Treatment regime } & \multirow{2}{*}{$\begin{array}{l}\text { Wilcoxon } \\
\text { W }\end{array}$} & \multirow[t]{2}{*}{$P$} \\
\hline & $\begin{array}{l}\text { Nonoperative group } \\
\text { Median }\left(\boldsymbol{P}_{75}-\boldsymbol{P}_{25}\right)\end{array}$ & $\begin{array}{l}\text { Arthroplasty group } \\
\text { Median }\left(P_{75}-P_{25}\right)\end{array}$ & & \\
\hline Age & $91.5(4.0)$ & $92.0(4.0)$ & 805.0 & 0.530 \\
\hline Length of stay & $8(17)$ & $18(59)$ & 458.5 & $<0.001^{*}$ \\
\hline Delay of Admission & $3(9.60)$ & $1(3.71)$ & 630.5 & $0.053^{*}$ \\
\hline Survival time (months) & $22(52)$ & $53(59)$ & 514.0 & $0.001^{*}$ \\
\hline BMI & $17.7(3.2)$ & $19.1(3.0)$ & 582.0 & $0.009^{*}$ \\
\hline \multicolumn{5}{|l|}{ Laboratory parameters } \\
\hline WBC & $7.23(3.83)$ & $7.95(3.68)$ & 846.0 & 0.914 \\
\hline Platelets & $166(98)$ & $161(119)$ & 794.0 & 0.475 \\
\hline BUN & $7.51(5.86)$ & $6.92(3.47)$ & 791.5 & 0.461 \\
\hline INR & $1.09(0.11)$ & $1.08(0.12)$ & 742.0 & 0.239 \\
\hline Creainine & $75.50(46)$ & $79.60(37)$ & 849.0 & 0.821 \\
\hline Sodium & $138.15(7.20)$ & $139.20(6.90)$ & 874.0 & 0.996 \\
\hline Billirubin & 13.05 (10.60) & $14.60(7.40)$ & 746.0 & 0.254 \\
\hline
\end{tabular}

${ }^{*} P<0.05$ was considered statistically significant 
Table 4 The compare of cumulative mortality after injury between two groups

\begin{tabular}{|c|c|c|c|c|}
\hline \multirow{2}{*}{$\begin{array}{l}\text { Cumulative } \\
\text { mortality } \\
\text { after injury }\end{array}$} & \multicolumn{2}{|l|}{ Treatment regime } & \multirow[t]{2}{*}{$x^{2}$} & \multirow[t]{2}{*}{$P$} \\
\hline & Nonoperative group N (\%) & Arthroplasty group N(\%) & & \\
\hline $0-30$ days & $9(17.0)$ & $3(9.1)$ & 1.055 & 0.304 \\
\hline 0-1 year & $23(43.4)$ & $4(12.1)$ & 9.236 & $0.002^{*}$ \\
\hline $0-2$ year & $27(50.9)$ & $8(24.2)$ & 6.008 & $0.014^{*}$ \\
\hline 0-3 year & $34(64.2)$ & $13(39.4)$ & 5.029 & $0.025^{*}$ \\
\hline 0-4 year & $38(71.7)$ & $15(45.5)$ & 5.923 & $0.015^{*}$ \\
\hline $0-5$ year & $42(79.2)$ & $17(51.5)$ & 7.261 & $0.007^{*}$ \\
\hline Total & 42 (79.2) & $17(51.5)$ & 7.261 & $0.007^{*}$ \\
\hline
\end{tabular}

${ }^{*} P<0.05$ was considered statistically significant

the first in the world to assess this critical issue in a lowor middle-income country, with a timeline spanning more than 16 years.

The chance of surviving to the age of 90 has increased markedly over the last 50 years [21]. The life expectancy for 90-year-olds (ranging from 4 to 5 years) in most high-income countries is still reasonably shorter than that for 80 -year-olds (ranging from 8 to 10 years) [21]. Recently, two successive cohort studies from China presented results consistent with the results from developed countries $[22,23]$. Liu et al. demonstrated that the life expectancy of the population aged 90-99 years was 3.94.0 years [22].

Some studies have shown that the overtreatment of extremely elderly individuals is still a general concern, and potential side effects of treatment have to be balanced with the overall survival prognosis, which is generally based on the overall chance of survival to a given age or overall life expectancy [21, 24]. It has been argued that clinicians should discuss overall survival prognosis with patients aged 85 and older [24].

On the other hand, there is a lack of consensus on the definition of long-term survival for hip fracture patients aged 90 and older. Some recent studies demonstrated that the mortality rates in nonagenarian hip fracture patients were equivalent to the mortality rates in the average population at 5 years after injury $[9,12-16]$. Less than $5 \%$ of patients survive for more than 10 years [16]. Consequently, the five-year survival rate can be considered a reliable parameter to reflect the long-term outcomes of extremely elderly patients with hip fracture.

During the past several decades, the dilemma of how to optimize care for extremely elderly hip fracture patients has included two aspects. First, previous reports on hip fracture patients aged older than 90 years mainly focused on 30-day and 1-year mortality and paid little attention to the survival status at 2 years or more. Second, many studies previously evaluated long-term mortality in hip fracture patients, but only a few assessed the survival of nonagenarian hip fracture patients [9, 11, 17, 25, 26].

Compared to other investigations on short-term mortality after surgery for hip fracture, our 30-day rates were similar (9.1\% versus a range from 5.6 to $9.6 \%)[6,10,11$, $17,27,28]$. An exception is a Taiwan investigation in which $95.4 \%$ of patients survived to 30 days, which is the lowest mortality rate in nonagenarian femoral neck fracture patients in the literature [16]. Some studies have revealed results that conflict with those in the current study, in which 30-day mortality was higher than $10 \%$ [7, $26,29]$. These discrepancies may be partially due to different social and cultural aspects, policies, and health

Table 5 The log-rank test for survival length during the different time interval between two groups

\begin{tabular}{|c|c|c|c|c|}
\hline \multirow{2}{*}{$\begin{array}{l}\text { Different } \\
\text { Time } \\
\text { intervals }\end{array}$} & \multicolumn{2}{|l|}{ Treatment regime } & \multirow[t]{2}{*}{$x^{2}$} & \multirow[t]{2}{*}{$P$} \\
\hline & Nonoperative group $\left(\bar{x} \pm s_{d}\right)$ & Arthroplasty group $\left(\bar{x} \pm s_{d}\right)$ & & \\
\hline$(0,30]$ days & $34.78 \pm 4.26$ & $62.00 \pm 7.04$ & 10.017 & $0.002^{*}$ \\
\hline$(0,1]$ year & $40.01 \pm 4.45$ & $57.93 \pm 7.18$ & 5.021 & $0.025^{*}$ \\
\hline$(1,2]$ year & $31.56 \pm 4.22$ & $62.62 \pm 7.45$ & 12.373 & $<0.001^{*}$ \\
\hline$(2,3]$ year & $33.56 \pm 4.49$ & $64.00 \pm 7.75$ & 11.100 & $0.001^{*}$ \\
\hline$(3,4]$ year & $30.85 \pm 4.30$ & $58.82 \pm 7.48$ & 10.048 & $0.002^{*}$ \\
\hline$(4,5]$ year & $30.58 \pm 4.35$ & $58.93 \pm 7.80$ & 5.021 & $0.025^{*}$ \\
\hline Total & $31.36 \pm 4.22$ & $73.26 \pm 11.65$ & 9.568 & $0.002^{*}$ \\
\hline
\end{tabular}

* $P<0.05$ was considered statistically significant 

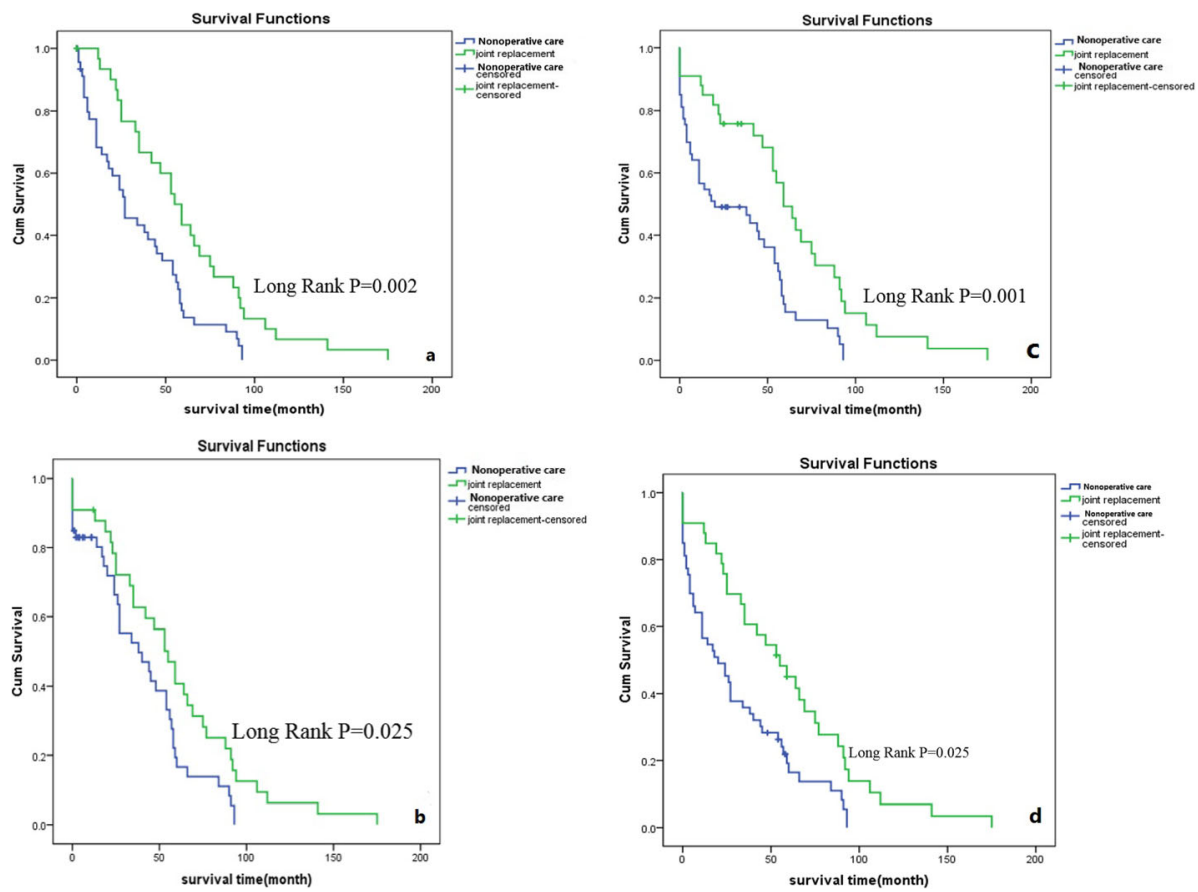

Fig. 1 a. Shown the overall survival of the arthroplasty group is significant higher than the nonoperative treatment group (Log-rank $P=0.002)$. bd. The 1-year (b), 3-year (c) and 5-year survival (d) distribution difference between two groups is significance (Log-rank $P=0.025)$, (Log-rank $P=$ 0.001) and (Log-rank $P=0.025)$, respectively

system services. Advances in medications, lifestyles, and socioeconomic status might also contribute to these mixed survival outcomes.

Based on national data from the Chinese Longitudinal Healthy Longevity Study, 7234 individuals who survive to 90 years of age have an all-cause annual mortality rate of $22.4-23.4 \%$ [23]. An earlier published study found that the expected 1-year survival rate for the average Japanese population aged 90 years and older was $83.7 \%$ in women and $77.6 \%$ in men [30]. In our study, the 1year mortality rates in the arthroplasty and nonoperative groups were 12.1 and $43.4 \%$, respectively. One of the possible reasons for this difference is the surgical treatment of the femoral neck fracture, no longer increasing the mortality compared with the general population during the last two decades [31].

Our 1-year mortality result is also consistent with another study performed in North China. In this multicenter retrospective study of 327 nonagenarian individuals, Liu et al. showed that the 1-year mortality after surgery was $11.6 \%$ [32]. Previous studies demonstrated that 1 -year mortality in nonagenarian femoral neck patients varied from 23.3 to $47.6 \%$ [6, $16,30,33-35]$. Although our 1-year mortality rate in the arthroplasty group was lower than those in the previously mentioned studies, it was similar to other studies [11, 36]. Another possible explanation for the differences in mortality rates between this study and previous studies might be related to different demographics, including age, sex distributions, and comorbidities in each study.

Limited studies have demonstrated that five-year mortality in hip fracture patients varies from 55 to $82 \%$ [11, $16,17,26]$. After a retrospective analysis of a total of 149 patients, de Leur et al. found that five-year survival in nonagenarian hip fracture patients was $18 \%$ after osteosynthesis [17]. In a large nationwide database study of 11,184 nonagenarian patients undergoing surgery for hip fracture in Taiwan, the mortality rates increased from $29.5 \%$ at 1 year to $78.1 \%$ at 5 years after surgery [16]. Lin et al. also demonstrated that 10-year mortality was $95.90 \%$, which means that less than $5 \%$ of patients survived more than 10 years [16]. The five-year mortality $(51.5 \%)$ in the arthroplasty group in this study was consistent with the results of Gregory et al. (55\%) and Knauf et al. $(61.5 \%)[11,25]$ but higher than those in the two previously mentioned studies $[16,17]$.

The survival time in the arthroplasty group was significantly higher than that in the nonoperative group (53 months versus 22 months, $p=0.001$ ). This gap in survival time may be a result of highly selective patient recruitment in that series, resulting in only 33 nonagenarians operated on over 16 years. Large-sample and multicenter studies deserve to be comprehensively evaluated to obtain a clear understanding of long-term survival among these patients. 
In our study, we found a higher 5-year survival probability in the arthroplasty group than in the nonoperative treatment group $(39.3 \%, 13 / 33$ versus $11.3 \%, 6 / 53, p=$ 0.002). Manton et al. showed that the five-year survival probability in Japanese individuals aged 90 years ranged from 22.7 to $33.0 \%$ [37]. In the Netherlands, the survival rate of people aged 90 years increased from $19.45 \%$ in 1990 to $31.4 \%$ in 2016 [38]. Compared with the observed survival probability of patients in the current study, the survival rate in the nonoperative group (11.3\%) was less than that in the average population, and that in the arthroplasty group (39.3\%) was similar to that in the average population. Although the sample size was limited, the results can partially reflect the advantage of surgery for long-term survival among this unique group of patients. This encouraging result supports the rapid increase in healthcare expenditures and infrastructure development and the recent implementation of universal healthcare coverage in China [23].

One unique aspect of this study was that the number of patients who self-selected nonoperative care was higher than that in the arthroplasty group. Although operative treatment for femoral neck fractures is prevalent in developed countries, preoperative discussions with some Chinese patients and family caregivers may be challenging to initiate because of low educational levels or cultural taboos about discussing death [39]. Selection bias regarding patients who underwent arthroplasty may explain some of these disparities; however, there is no doubt that unequal outcomes between China and Western developed countries are multifactorial in origin, and factors such as trust in physicians and medication adherence may play a role [40].

The primary strength of this study was the data collection, low rate of loss to follow-up $(<3 \%)$, and duration of follow-up, which was more than 10 years; it was the longest of any published series and exceeded the life expectancy for this age group. This cohort was followed for more than 10 years, which eliminated the bias effect of demographic changes. To the authors' knowledge, this is the most extensive study to date comparing nonoperative treatment and arthroplasty in patients with femoral neck fracture over 90 years of age.

The interpretation of the findings of our study must comprehensively consider the limitations of our study design. The limitations of our research are inherent to the nature of retrospective reviews performed in a single teaching hospital. Future longitudinal and multicenter studies should be conducted to establish practice guidelines for the treatment of femoral neck fracture in extremely elderly patients. Second, selection bias and other unconscious bias associated with the survival outcome in this study should be considered unique issues. Further research is needed to better understand the effect of these biases on the survival outcome among Chinese or Asian hip fracture patients. Finally, because this study did not include intertrochanteric fractures, our conclusions are not representative of all nonagenarian and centenarian hip fractures.

\section{Conclusion}

Our study suggests that arthroplasty is more likely to improve long-term survival in femoral neck fracture patients over the age of 90 than nonoperative treatment. It can be expected that nearly half of patients will survive more than 5 years after surgery. This subpopulation can be treated similarly to younger elderly patients if initial preoperative assessment suggests comparable health. Although inherent selection bias and unconscious bias existed in this retrospective study, our findings offer valuable information for orthopedic surgeons by providing long-term survival data to enhance critical patientclinician discussions.

\section{Abbreviations}

BMI: Body mass index; CCl: Charlson comorbidity index; ASA: American Society of Anesthesiologists; URBMI: The Urban Resident Basic Medical Insurance; UEBMI: The Urban Employee Basic Medical Insurance; NRCMS: The New Rural Cooperative Medical Scheme

\section{Acknowledgements}

Not applicable.

\section{Authors' contributions}

All authors participated in the design of the study. YL and ZXD collected the data. YL set up the dataset and performed the analysis with support from CWZ. YL was a major contributor in writing the manuscript. All authors participated in revising the manuscript. All authors read and approved the final manuscript.

\section{Funding}

This work was supported by the grant from the Applied Basic Research Programs of Science and Technology Commission Foundation of Sichuan Province (No. 2012JY0084) and Research Programs of Health and Family Planning Commission of Sichuan Province (No.150165). The funder had no role in the study design, data collection, analysis, interpretation of data or writing of the manuscript.

\section{Availability of data and materials}

The datasets used and/or analyzed during the current study are available from the corresponding author on reasonable request.

\section{Ethics approval and consent to participate}

The study was approved by Biomedical Ethics Sub-Committee of West China Hospital of Sichuan University (ref. 2017/48). Upon registration in West China Hospital of Sichuan University, the patients accept that their data maybe used in research. No further approval from the patients has, therefore, been sought for this study. Informed consent: No consent was required. Only general non-identifiable data on a series of patients is included. All data are presented on an aggregated level, and the individual patient cannot be identified.

\section{Consent for publication}

Not applicable.

Competing interests

The authors declare that they have no competing interests. 


\section{Author details}

Department of Orthopedic Surgery, National Clinical Research Center for Geriatrics, West China Hospital of Sichuan University, Wai Nan Guo Xue Lane No. 37, Wuhou District, Chengdu, Sichuan Province, P.R. China 610041. ${ }^{2}$ Department of Laboratory Medicine, West China Hospital of Sichuan University, Wai Nan Guo Xue Lane No. 37, Wuhou District, Chengdu, Sichuan Province, P.R. China 610041.

\section{Received: 3 January 2020 Accepted: 27 March 2020}

Published online: 08 April 2020

\section{References}

1. United Nations, Department of Economic and Social Affairs, Population Division (2017). World population ageing 2017 (ST/ESA/SER.A/408). (Access from: https://population.un.org/ProfilesOfAgeing2017/index.html). Accessed 15 Oct 2018.

2. Barbi E, Lagona F, Marsili M, Vaupel JW, Wachter KW. The plateau of human mortality: demography of longevity pioneers. Science. 2018;360(6396):1459-61

3. Bhandari M, Swiontkowski M. Management of acute hip fracture. N Engl J Med. 2017:377:2053-62.

4. Yu F, Xia W. The epidemiology of osteoporosis, associated fragility fractures, and management gap in China. Arch Osteoporos. 2019;14(1):32.

5. Tian FM, Sun XX, Liu JY, Liu ZK, Liang CY, Zhang L. Unparallel genderspecific changes in the incidence of hip fractures in Tangshan, China. Arch Osteoporos. 2017;12(1):18.

6. Chia PH, Gualano L, Seevanayagam S, et al. Outcomes following fractured neck of femur in an Australian metropolitan teaching hospital. Bone Joint Res. 2013;2:162-8.

7. Hapuarachchi KS, Ahluwalia RS, Bowditch MG. Neck of femur fractures in the over 90s: a select group of patients who require prompt surgical intervention for optimal results. J Orthop Traumatol. 2014:15:13-9.

8. Barceló M, Francia E, Romero C, et al. Hip fractures in the oldest old. Comparative study of centenarians and nonagenarians and mortality risk factors. Injury. 2018;49(12):2198-202.

9. Bokshan SL, Marcaccio SE, Blood TD, Hayda RA. Factors influencing surviva following hip fracture among octogenarians and nonagenarians in the United States. Injury. 2018:49(3):685-90.

10. van de Kerkhove MP, Antheunis PS, Luitse JS, Goslings JC. Hip fractures in nonagenarians: perioperative mortality and survival. Injury. 2008:39(2):244-8.

11. Gregory JJ, Starks I, Aulakh T, Phillips SJ. Five-year survival of nonagenarian patients undergoing total hip replacement in the United Kingdom. J Bone Joint Surg (Br). 2010;92(9):1227-30.

12. Bliuc $D$, Nguyen $N D$, Milch VE, et al. Mortality risk associated with lowtrauma osteoporotic fracture and subsequent fracture in men and women JAMA. 2009;301(5):513-21.

13. Mnif $\mathrm{H}$, Koubaa M, Zrig M, et al. Elderly patient's mortality and morbidity following trochanteric fracture. A prospective study of 100 cases. Orthop Traumatol Surg Res. 2009:95(7):505-10.

14. Lee AY, Tan J, Koh J, et al. Five-year outcome of individuals with hip fracture admitted to a Singapore hospital: quality of life and survival rates after treatment. J Am Geriatr Soc. 2012;60(5):994-6.

15. Johnston AT, Barnsdale L, Smith R, Duncan K, Hutchison JD. Change in long-term mortality associated with fractures of the hip: evidence from the scottish hip fracture audit. J Bone Joint Surg (Br). 2010;92(7):989-93.

16. Lin JC, Liang WM. Mortality, re-admission, and reoperation after hip fracture in nonagenarians. BMC Musculoskelet Disord. 2017;18(1):144.

17. de Leur K Vroemen JP, Vos DI, Elmans L, van der Laan L. Outcome after osteosynthesis of hip fractures in nonagenarians. Clin Interv Aging. 2014;9:41-9.

18. Schilling PL, Bozic KJ. Development and validation of perioperative riskadjustment models for hip fracture repair, Total hip Arthroplasty, and Total knee Arthroplasty. J Bone Joint Surg Am. 2016;98:e2.

19. Charlson ME, Pompei P, Ales KL, MacKenzie CR. A new method of classifying prognostic comorbidity in longitudinal studies: development and validation. J Chronic Dis. 1987:40:373-83.

20. Owens WD, Felts JA, Spitznagel EL Jr. ASA physical status classifications: a study of consistency of ratings. Anesthesiology. 1978:49:239-43.

21. Thinggaard M, MCGue M, Jeune B, Osler M, Vaupel JW, Christensen K. Survival prognosis in very old adults. J Am Geriatr Soc. 2016:64(1):81-8.

22. Liu Z, Han L, Feng Q, Dupre ME, Gu D, Allore HG, Gill TM, Payne CF. Are China's oldest-old living longer with less disability? A longitudinal modeling analysis of birth cohorts born 10 years apart. BMC Med. 2019;17(1):23.
23. Zeng Y, Feng Q, Hesketh T, Christensen K, Vaupel JW. Survival, disabilities in activities of daily living, and physical and cognitive functioning among the oldest-old in China: a cohort study. Lancet. 2017;389(10079):1619-29.

24. Smith AK, Williams BA, Lo B. Discussing overall prognosis with the very elderly. N Engl J Med. 2011;365(23):2149-51.

25. Knauf T, Bücking B, Bargello M, Ploch S, Bliemel C, Knobe M, Ruchholtz S, Eschbach D. Predictors of long-term survival after hip fractures?-5-year results of a prospective study in Germany. Arch Osteoporos. 2019;14(1):40.

26. Lin WT, Chao CM, Liu HC, Li YJ, Lee WJ, Lai CC. Short-term outcomes of hip fractures in patients aged 90 years old and over receiving surgical intervention. PLoS One. 2015:10(5):e0125496.

27. Graver A, Merwin S, Collins L, Kohn N, Goldman A. Comorbid profile rather than age determines hip fracture mortality in a nonagenarian population. HSS J. 2015;11(3):223-35.

28. Roche JJ, Wenn RT, Sahota O, Moran CG. Effect of comorbidities and postoperative complications on mortality after hip fracture in elderly people: prospective observational cohort study. BMJ. 2005:331(7529):1374.

29. Kirkland LL, Kashiwagi DT, Burton MC, Cha S, Varkey P. The Charlson comorbidity index score as a predictor of 30-day mortality after hip fracture surgery. Am J Med Qual. 2011;26(6):461-7.

30. Ishida Y, Kawai S, Taguchi T. Factors affecting ambulatory status and survival of patients 90 years and older with hip fractures. Clin Orthop Relat Res. 2005;436:208-15.

31. Schneppendahl J, Grassmann JP, Petrov V Böttner F, Körbl B, Hakimi M, Betsch $M$, Windolf J, Wild M. Decreasing mortality after femoral neck fracture treated with bipolar hemiarthroplasty during the last twenty years. Int Orthop. 2012;36(10):2021-6.

32. Liu Y, Peng M, Lin L, Liu X, Qin Y, Hou X. Relationship between American Society of Anesthesiologists (ASA) grade and 1-year mortality in nonagenarians undergoing hip fracture surgery. Osteoporos Int. 2015;26(3):1029-33.

33. Shah MR, Aharonoff GB, Wolinsky P, Zuckerman JD, Koval KJ. Outcome after hip fracture in individuals ninety years of age and older. J Orthop Trauma. 2001:15(1):34-9.

34. Sanz-Reig J, Lizaur-Utrilla A, Serna-Berna R. Outcomes in nonagenarians after hemiarthroplasty for femoral neck fracture. A prospective matched cohort study. Hip Int. 2012;22(1):113-8.

35. Kim JW, Kim DH, Jang EC, Lee YK, Koo KH, Ha YC. Mortality and its risk factors in nonagenarians after hip fractures. J Orthop Sci. 2019;24(5):850-4 pii: S0949-2658(19)30071-30075.

36. Kadowaki M, Kono M, Nishiguchi K, Kakimaru H, Uchio Y. Mortality in patients with hip fracture aged over 90 years: a report from a progressively aging island. Arch Gerontol Geriatr. 2012;54(2):e113-7.

37. Manton KG, Vaupel JW. Survival after the age of 80 in the United States, Sweden, France, England, and Japan. N Engl J Med. 1995:333(18):1232-5.

38. Centraal bureau voor de statistiek, Medische jaaroverzicht 2017. (Access from: https:// www. cbs.nl/ en-gb/news/2017/44/life-expectancy-at-age-65. ).Accessed 15 Oct 2018.

39. Cagle JG, McClymont KM, Thai JN, Smith AK. "If you don't know, all of a sudden, they're gone": caregiver perspectives about prognostic communication for disabled elderly adults. J Am Geriatr Soc. 2016;64(6):1299-306.

40. Santry HP, Wren SM. The role of unconscious bias in surgical safety and outcomes. Surg Clin North Am. 2012;92(1):137-51.

\section{Publisher's Note}

Springer Nature remains neutral with regard to jurisdictional claims in published maps and institutional affiliations.

Ready to submit your research? Choose BMC and benefit from

- fast, convenient online submission

- thorough peer review by experienced researchers in your field

- rapid publication on acceptance

- support for research data, including large and complex data types

- gold Open Access which fosters wider collaboration and increased citations

- maximum visibility for your research: over $100 \mathrm{M}$ website views per year

At BMC, research is always in progress.

Learn more biomedcentral.com/submission 